\title{
Highly subcooled pool boiling heat transfer at various gravity levels
}

\author{
Jungho Kim ${ }^{\mathrm{a}, *}$, John F. Benton ${ }^{\mathrm{b}}$ \\ a Department of Mechanical Engineering, University of Maryland, College Park, MD 20742, USA \\ b Schlumberger Completions Product Center, 7030 Ardmore Street, Houston, TX 77054, USA
}

Received 19 October 2001; accepted 11 January 2002

\begin{abstract}
A microscale heater array $2.7 \mathrm{~mm} \times 2.7 \mathrm{~mm}$ in size along with a video camera was used to provide subcooled pool boiling heat transfer measurements at gravity levels ranging from $1.8 \mathrm{~g}$ to $10^{-6} \mathrm{~g}$. The fluid was $\mathrm{FC}-72$ at 1 atm and subcooled by nominally $36^{\circ} \mathrm{C}$ for all cases. A Terrier-Orion sounding rocket and the $\mathrm{KC}-135$ aircraft were used to provide the microgravity and low- $g$ environments, respectively. The data indicate that there is little effect of gravity on boiling heat transfer at wall superheats below $25^{\circ} \mathrm{C}$, even though there are large differences in bubble behavior between gravity levels. At higher superheats, the low- $g$ data fell significantly below the $1 \mathrm{~g}$ and $1.8 \mathrm{~g}$ data due to a large part of the heater surface drying out. A large primary bubble was observed to form and move over the surface in low- $g$, occasionally causing nucleation to occur. This primary bubble was surrounded by smaller bubbles which eventually merged with it. The primary bubble initially formed by the coalescence of smaller bubbles generated on the surface, but then remained constant in size for a given superheat, indicating a balance between evaporation at the bubble base and condensation on the bubble cap. The size of the primary bubble increased with increasing wall superheat. Most of the heaters under the primary bubble indicated low heat transfer, consistent with dryout on the heater surfaces. Strong Marangoni convection around the bubble was observed to develop in low-g, forming a "jet" of heated fluid into the bulk fluid. (C) 2002 Elsevier Science Inc. All rights reserved.
\end{abstract}

Keywords: Pool boiling; Microgravity; Subcooling

\section{Introduction}

An understanding of boiling and critical heat flux in microgravity environments is important to the design of future heat removal equipment for use in space-based applications. Although much research in this area has been performed since the Space Station was proposed, the mechanisms by which heat is removed from surfaces under these environments are still unclear. Many of the early experimental studies regarding boiling heat transfer in microgravity environments were first performed under NASA sponsorship in drop towers (see Siegel (1967) and Clark (1968) for a review), and were mainly concerned with determining whether or not gravity affected the boiling process. The results of these early experiments were somewhat contradictory, with some experiments showing no effect of gravity on heat transfer \footnotetext{
9477.

${ }^{*}$ Corresponding author. Tel.: +1-301-405-5437; fax: +1-301-314-

E-mail address: kimjh@eng.umd.edu (J. Kim).
}

and others showing a strong dependence. Much of the discrepancy can be attributed to the relatively short test times that were available since convection effects from before drop initiation could not be eliminated during the short drop time. Visual observations of the boiling process, however, revealed that a large increase in bubble size (up to a few millimeters) occurred under low- $g$ conditions, with small bubbles coalescing into larger bubbles a small distance from the heater. Siegel and Keshock (1964), e.g., found the bubble departure radius to vary approximately as $a^{-1 / 3}$ for $0.1<a / g<1$, and according to $a^{-1 / 2}$ for lower gravities.

Straub and co-workers have been looking at boiling in microgravity environments under sponsorship of the German Department of Research and Technology since the early 1980s (Zell et al., 1984; Vogel and Straub, 1992; Zell et al., 1989, 1990). Investigations were carried out using sounding rockets (test times of up to $6 \mathrm{~min}$ ) under the TEXUS program, and using NASA's KC 135 aircraft (test times of about $25 \mathrm{~s}$ per parabolic flight path). Boiling curves from both wires and flat plates at 
saturated and subcooled conditions were obtained for Freon 12, Freon 113, and water. Results from their work indicated that gravity has little effect on the overall heat transfer from flat plates-heater temperatures remained constant for given heat fluxes for $\pm 0.03<a / g<$ 1.8 , although large increases in the bubble departure radius were observed. Bubble departure was felt to occur as a result of the inertia imparted to the surrounding liquid during bubble growth, which subsequently pulled the bubble away from the heated surface. The researchers concluded that buoyancy effects are replaced by surface tension effects (coalescence and evaporationcondensation) in low-g, so the overall level of heat transfer remains about the same. These authors felt that evaporation was the primary heat transfer mechanism.

Merte has also performed many experiments over the years. Lee and Merte (1998) describe the results of boiling experiments using R-113 from five space flights between 1992 and 1996. They used a gold film $(19 \mathrm{~mm} \times 38 \mathrm{~mm})$ sputtered on a quartz substrate as both heater and temperature sensor. Boiling behavior under a wide range of heat fluxes and subcoolings was obtained. They observed eventual dryout of the surface under high heat fluxes at saturated conditions, but steady nucleate boiling at the same heat flux when the subcooling was increased to $22{ }^{\circ} \mathrm{C}$. When steady nucleate boiling was observed, a very large bubble above the surface acted as a reservoir for numerous smaller bubbles growing on the heater surface. The large bubble maintained its size due to a balance between condensation at the top of the bubble and coalescence with the smaller bubbles at its base. Enhancements in the heat transfer of up to $32 \%$ were observed in microgravity compared to earth gravity. Marangoni convection was also observed to play a significant role in the enhancement of heat transfer since it caused large vapor bubbles to be impelled toward the heater surface and small bubbles to migrate to the heater surface. Increased subcooling was associated with an increase in heat transfer level. However, CHF appeared to decrease significantly in microgravity.

Ohta et al. (1997) measured the heat transfer, local temperature, and local liquid film thickness during boiling of ethanol on a sapphire substrate under microgravity using a NASDA TR-1A rocket. Local heat transfer was calculated using a numerical simulation of the transient heat conduction within the central $50 \mathrm{~mm}$ of the sapphire substrate. Boundary condition information was provided by a row of platinum, thin-film temperature sensors deposited directly onto the surface of the substrate. For highly subcooled boiling, small bubbles on the surface of the heater were observed with condensation occurring at the top of the bubbles, and steady-state boiling was observed to occur.

Oka et al. (1995) studied pool boiling of organics and water using a heater made of $50 \mathrm{~mm} \times 50 \mathrm{~mm}$ ITO on glass substrate. Parabolic aircraft and a drop tower used to produce the low- $g$ and microgravity environments. Boiling of organics resulted in bubbles attached to the surface with consequent dryout. Coalescence of bubbles occurred while bubbles were on the surface. Bubbles during boiling of organics were spherical, and made slight contact with the heater or were lifted off the surface. Coalescence occurred a small distance away from the surface. They found that boiling heat transfer in low$g$ deteriorated for water throughout the boiling regime compared to $1 g$. Significant deterioration for organics only occurred at higher heat fluxes. Differences in the surface tension and surface wettability were cited as reasons for the differences in boiling behavior.

The experiments to date have shown that stable, subcooled boiling on flat plates in microgravity environments is possible, although usually with some alteration in heat transfer coefficients. It is important to note, however, that most research pertaining to boiling in microgravity environments has thus far been either of a qualitative nature (photographic studies) with some wall heat flux/wall temperature measurements, analytical work, or numerical simulations. In the studies where heat transfer coefficients were measured, the heated surfaces were always comparable to, or much larger than, the bubble sizes so only average heat transfer rates over the entire heated surface were obtained. Little experimental data is available regarding the local heat transfer rates under and around the bubbles as they grow and depart from the surface. Better understanding of the heat transfer mechanisms involved in the boiling process can be attained by pinpointing when and where in the bubble departure cycle large amounts of heat are removed from the wall, and correlating this information to visual observations of the state of the bubble at those times. Such information can provide much needed data regarding the important heat transfer mechanisms during the bubble departure cycle, and can serve as benchmarks to validate many of the analytical and numerical models used to simulate boiling. Another technologically important area in which little research has been performed is the effect of microgravity on critical heat flux. Although it is known that decreasing gravity decreases the critical heat flux level (e.g. Straub et al., 1990), little quantitative data is available. Improved knowledge of the mechanisms controlling the boiling process will improve the reliability and performance of space-based heat removal equipment. The reader is referred to the review papers by Straub (2001) and Di Marco and Grassi (2000) for additional information on microgravity pool boiling.

In this work, the effects of gravity on highly subcooled pool boiling were studied using an array of microscale heaters similar to those used by the author previously for earth gravity measurements (Rule and Kim, 1999) and for low-g saturated conditions 
(Kim et al., 2001). As part of this effort, a new experimental apparatus was designed, built, and flown on the Terrier-Orion sounding rocket. Additional data was taken subsequent to this flight using the same rig and heater array, but on the $\mathrm{KC}-135$. The bulk fluid was subcooled by nominally $36^{\circ} \mathrm{C}$ for all the test cases.

\section{Test apparatus}

\subsection{Heater array}

Local heat flux measurement and temperature control was performed using an array of platinum resistance heater elements deposited on a quartz wafer in a serpentine pattern. Each of these elements was $0.27 \mathrm{~mm} \times$ $0.27 \mathrm{~mm}$ in size, had a nominal resistance of $1000 \Omega$, and a nominal temperature coefficient of resistance of 0.002 $\mathrm{K}^{-1}$. Ninety-six individual heaters were arranged in a square array about $2.7 \mathrm{~mm}$ on a side. The reader is referred to Rule and Kim (1999) for details.

\subsection{Electronics}

The feedback electronics used in this series of tests were similar to those used in previous tests, and are described in Bae et al. (1999), but were redesigned so there were four feedback boards each containing 24 circuits and one data acquisition/control card. The temperature of each heater in the array was maintained at a constant value by feedback circuits similar to those used in constant-temperature hot-wire anemometry (Fig. 1). The op-amp measured the imbalance in the bridge and provided an output of whatever voltage was needed to keep the ratio $R_{\mathrm{u}} / R_{\mathrm{h}}$ equal to the resistance ratio on the right side of the bridge.

The heater resistance, and thus the heater temperature, was kept constant by varying the resistance of a digital potentiometer from Dallas Semiconductor

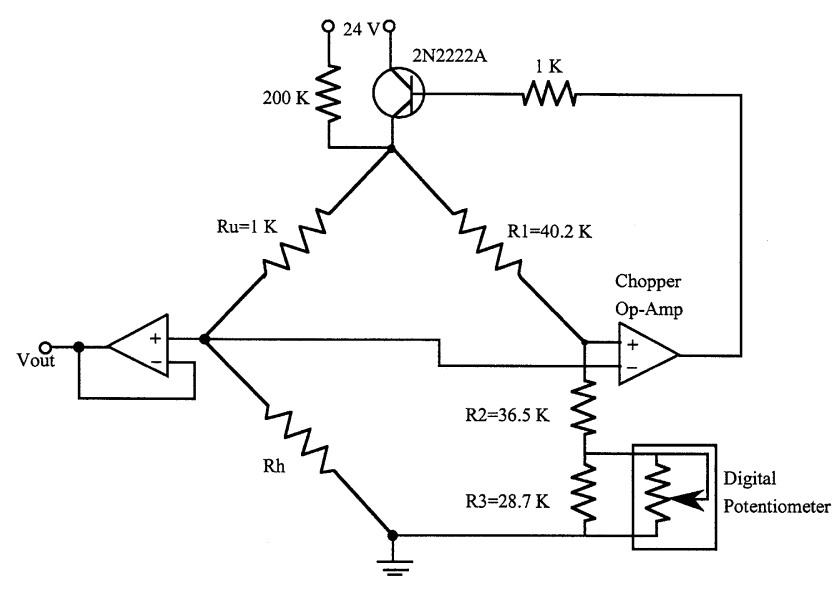

Fig. 1. Schematic of an electronic feedback loop.
(DS1267). This chip consists of two $10 \mathrm{k} \Omega$ digital potentiometers, each having 256 wiper positions. The two potentiometers in this chip were connected in series to make a single $20 \mathrm{k} \Omega$ potentiometer with 512 wiper positions. Control of the wiper position was performed through a 3-wire serial interface to a personal computer and digital $\mathrm{I} / \mathrm{O}$ card. For the resistor values indicated, a heater of nominally $1000 \Omega$ resistance could be varied over a $350 \Omega$ range. Since the heaters have a temperature coefficient of resistance of nominally $0.002 \mathrm{~K}^{-1}$, the temperature of the heaters could be varied by approximately $175 \mathrm{~K}$. Also, since the digital potentiometer had 512 settings, the temperature of the heaters could be changed in $\sim 0.34 \mathrm{~K}$ increments. The output of the circuit was the voltage required to keep the heater at a set temperature. The large $200 \mathrm{~K} \Omega$ resistor at the top of the bridge was used to provide a small trickle current through the heater, resulting in a voltage across the heater of about $100 \mathrm{mV}$ even when the op-amp was not regulating.

The data acquisition system (12 bit, $0-10 \mathrm{~V})$ was a custom built unit that multiplexed the output signals of the individual feedback loops, enabling the individual circuits to be sampled in any order. To acquire the output signal of a particular circuit, the address of that circuit was output from the computer to the data acquisition card, which then acquired a single sample from that particular circuit. The maximum sampling rate for the data acquisition was $50 \mathrm{kHz}$. If all 96 circuits were being sampled, then each heater could be sampled at a maximum rate of about $500 \mathrm{~Hz}$.

\subsection{Payload}

Shown in Fig. 2 is a schematic of the boiling rig used in this study. This rig is similar to one used previously by Kim et al. (2001) for measurements on the KC-135 aircraft, but the dome was made smaller so it would fit within the $36 \mathrm{~cm}$ diameter skin of the sounding rocket. The bellows and the surrounding housing allowed the test section pressure to be controlled. A stirrer was used to break up stratification within the test chamber, while a temperature controller and a series of Kapton heaters attached to the boiling chamber were used to control the bulk fluid temperature. The test chamber was filled with nominally 31 of FC-72. The fluid was degassed by periodically pulling a vacuum on it over a three day period. The final dissolved gas concentration in the liquid, determined using the chamber temperature and pressure and the properties of FC-72, was less than $1.5 \times 10^{-3}$ moles/mole.

The experiment payload consisted of the boiling chamber, a CCD video camera (Sony XC-75, $768 \times 494$ pixels, $6.4 \times 4.8 \mathrm{~mm}^{2}$ sensing area) with a long range microscope lens (VZM 300) to obtain images of bubble motion through the heater array, a VCR (TEAC 


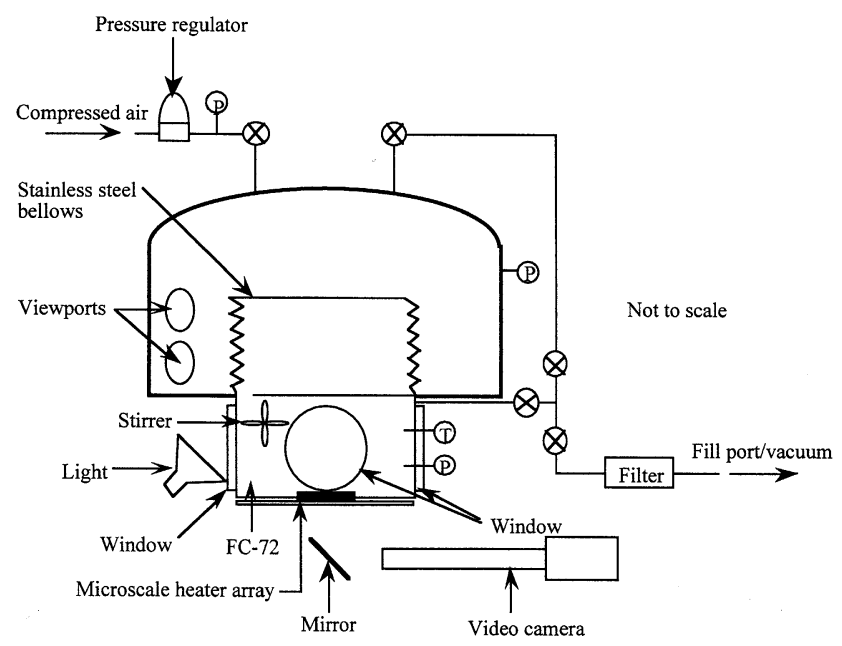

Fig. 2. Schematic of experimental apparatus.

V-80AB-F), and a PC-104 based $233 \mathrm{MHz}$ computer (real time devices CMW686GX233-64). An $80 \mathrm{MB}$ PCMCIA flash disk was used for data storage. A thermistor probe centered within the boiling chamber was calibrated to within $0.2{ }^{\circ} \mathrm{C}$ and provided a measure of the bulk fluid temperature. The absolute pressure within the boiling chamber was measured using a pressure transducer (Druck, PNP 4010, 0-3.4 atm, 0-5 VDC). Corrections were made for the changing weight of the fluid column above the transducer for the $1-g$ and high-g data. The video shutter speed was $1 / 2000 \mathrm{~s}$. Synchronization of the video with the data was performed by flashing the LEDs used to light the boiling chamber (a 4 bit combination of short and long flashes) to indicate the run number followed by continuous illumination during data acquisition.

A photograph of the payload is shown in Fig. 3. The payload was designed to withstand $50 \mathrm{~g}$ loads in all directions, much more than the $10 \mathrm{~g}$ load expected during launch of the rocket. Vibration testing of the payload was performed to verify that the components could survive the launch.

The acceleration environment was measured using NASA's SAMS-FF system. This system consists of a triaxial sensor head capable of measuring linear accelerations between 0.1 and $200 \mathrm{~Hz}$ with a resolution of $0.1 \mu \mathrm{g}$ and a max scale of $1.25 \mathrm{~g}$. A fiber optic gyroscope with a resolution of $0.1^{\prime \prime}$ and a maximum scale of $190 \mathrm{deg} / \mathrm{s}$ was used to measure roll rates. Both sensors were placed within $0.3 \mathrm{~m}$ of the boiling chamber.

\section{Flight tests}

\subsection{Sounding rocket}

Launch of the sounding rocket from Wallops Island occurred on December 17, 1999, and 200 s of very high

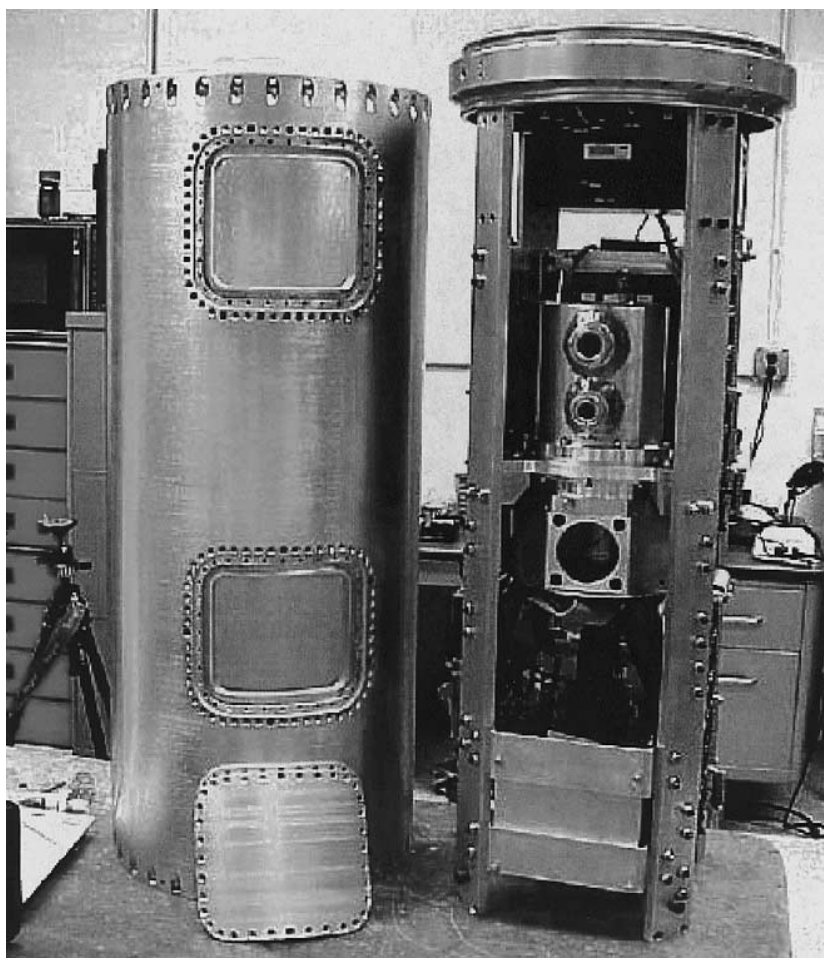

Fig. 3. Photograph of experimental apparatus.

quality microgravity $\left(10^{-6} g\right)$ with a maximum roll rate of $0.2 \mathrm{deg} / \mathrm{s}$ was achieved in all three axes. It was the quietest microgravity environment measured by NASA on any platform to date. All vehicle systems worked flawlessly. A maximum altitude of $164 \mathrm{~km}$ was reached. Splashdown occurred about 40 miles off the coast, and the payload was spotted by aircraft and picked up by the Coast Guard. Telemetry during the flight indicated that data acquisition initiated and data at all points in the test matrix were completed. Data was taken with the FC-72 at 1 arm $\left(T_{\text {sat }}=56^{\circ} \mathrm{C}\right)$ and a subcooling of $36{ }^{\circ} \mathrm{C}$ at a frequency of $250 \mathrm{~Hz} /$ heater. The first point in the matrix was a nucleation run where the heater temperature was set to about $110^{\circ} \mathrm{C}$ in order to start nucleation. The wall temperature was then decreased from $85^{\circ} \mathrm{C}$ down to $65^{\circ} \mathrm{C}$ in $5{ }^{\circ} \mathrm{C}$ increments. Data was collected for $25 \mathrm{~s}$ at each temperature. The sequence from $85^{\circ} \mathrm{C}$ down to $65{ }^{\circ} \mathrm{C}$ was then repeated.

Data from the flash disk was successfully recovered from the payload the morning after the flight. It was found that the VCR had failed to record, however, so no images of the bubble were obtained. The cause of this malfunction is currently not known, but is thought to be related to the orientation of the VCR in the payload. VCRs similar to those used in this test were successfully used in previous sounding rocket tests, but were mounted "right side up" relative to the nose of the rocket. The VCR in our payload was mounted "upside down", and this may have caused the tape to move off the drive momentarily during the high- $g$ portion of the 
launch, then not seat properly. No problems with the VCR were found during post-flight tests.

\section{2. $K C-135$}

In order to obtain additional data including video data, the experiment payload was repackaged to fly on the KC-135. The payload was mounted so that the heater was parallel to the floor of the aircraft, facing upwards. A second video camera was added to this package to obtain pictures of the bubbles from the side. The package was flown in late April, 2000 from the NASA Glenn Research Center. The same heater array used in the sounding rocket flight was used during the aircraft tests in order to minimize variation in heat transfer due to different nucleation site distributions. Flying the experiment on the KC-135 allowed data to be obtained at high- $g$ levels as well. Earth gravity data was taken after the $\mathrm{KC}-135$ flights were completed.

The acceleration environment in the $\mathrm{KC}-135$ was measured using the same accelerometer used to measure acceleration in the sounding rocket. These accelerometers, however, could only measure acceleration to $\pm 1.25 \mathrm{~g}$, so the actual $g$-level during the high- $g$ portion of the parabola can only be estimated to be between $1.6 \mathrm{~g}$ and $1.8 \mathrm{~g}$. The acceleration perpendicular to the floor of the aircraft was typically within $\pm 0.04 g$, but the rms could be up to $0.17 \mathrm{~g}$. The accelerations parallel to the floor of the aircraft was much better, with means within $\pm 0.01 \mathrm{~g}$ and rms smaller than $0.01 \mathrm{~g}$.

Data acquisition on the KC-135 was initiated about $10 \mathrm{~s}$ after low- $g$ was entered, and data was taken continuously for $90 \mathrm{~s}$ at a frequency of $250 \mathrm{~Hz} /$ heater. This allowed data to be obtained throughout the low-highlow gravity period. Video was obtained from below the heater array as well as from the side at $29.97 \mathrm{~Hz}$. The video images were de-interlaced and smoothed during post-processing, providing a series of images at 59.94 $\mathrm{Hz}$.

\section{Data reduction}

The energy supplied to the heater can be calculated from the voltage across the heater and the heater resistance $\left(q_{\text {raw }}\right)$. Part of this energy is lost through the substrate by conduction $\left(q_{\mathrm{sc}}\right)$, and part is transferred to the fluid $(q)$. Since the latter quantity is what is desired, $q_{\text {raw }}$ must be corrected to account for substrate conduction. The magnitude of this correction was determined as explained below.

The processes associated with boiling on any given heater can be identified from the heat flux variation with time. The term "boiling" in this work refers to the rapid growth and removal of bubbles, either by coalescence or buoyancy (in earth gravity), as indicated by the heat

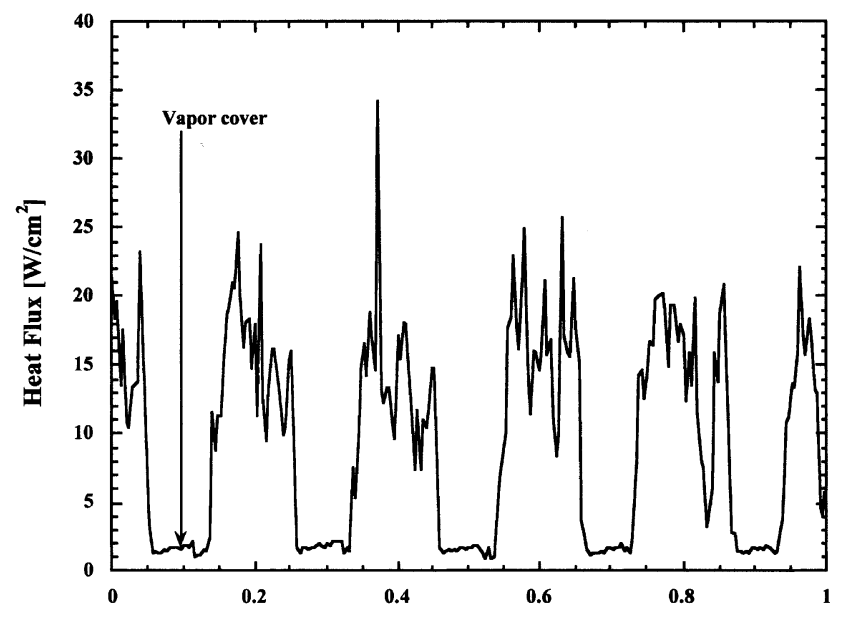

Fig. 4. Heat flux signal from a single heater in the array (heater \#32, wall superheat $=25^{\circ} \mathrm{C}$, low-g).

flux traces. The term "liquid" refers to liquid coming into contact with a heater without phase change for a relatively long time - such a situation could occur under natural convection conditions, or on a heater that is not influenced by bubbles nucleating around it. The term "vapor" refers to vapor coming into contact with the heater for a relatively long time - such a situation could occur when a large bubble covers a heater. The heat transfer from the wall to the fluid is very low in this case since the vapor insulates the surface.

Times when vapor covered the surface could be identified by the characteristically low and relatively steady heat flux - an example is shown in Fig. 4. Heat flux traces and the corresponding video revealed that boiling on any individual heater was interrupted by periods of low heat flux during which vapor covered the heater. Heat transfer to the bulk liquid during this time was minimal since the heaters were effectively insulated from the liquid, and was taken to be a measure of substrate conduction $\left(q_{\mathrm{sc}}\right)$. This was subtracted from $q_{\text {raw }}$ to obtain the heat flux from the wall to the fluid. The uncertainty in $q_{\mathrm{sc}}$ was estimated to be $1 \mathrm{~W} / \mathrm{cm}^{2}$. The distribution of $q_{\mathrm{sc}}$ on the surface at a temperature of 85 ${ }^{\circ} \mathrm{C}$ is shown in Fig. 5. Higher values are observed towards the edge of the array and in the corners, as expected.

\section{Results}

\subsection{Bubble behavior}

At all superheats in microgravity and low-g, a large primary bubble was observed to move over the surface, occasionally causing nucleation to occur as the dry spot moved over various heaters. This primary bubble moved in a circular path at the higher superheats, and more randomly on the surface at lower superheats. 


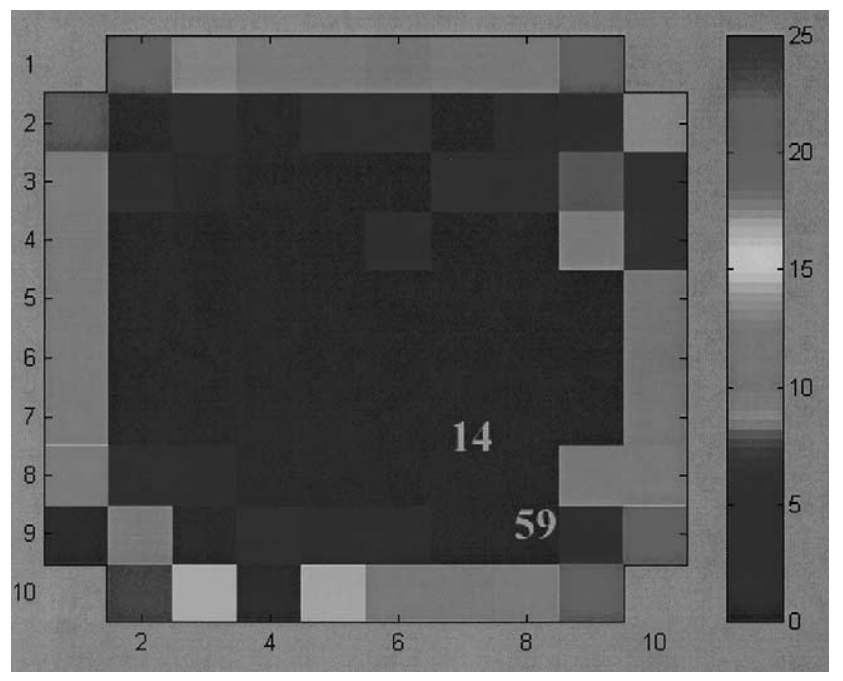

Fig. 5. Substrate conduction distribution on heater surface at $85^{\circ} \mathrm{C}$ during low- $g$. Color scale is in $\mathrm{W} / \mathrm{cm}^{2}$.

Photographs of the bubble behavior at three superheats during low- $g$ from the bottom and side are shown in Fig. 6. This primary bubble was surrounded by smaller satellite bubbles which eventually merged with the primary bubble. The primary bubble initially formed by the coalescence of satellite bubbles generated on the surface, but then remained relatively constant in size for a given superheat, indicating a balance between evaporation at the bubble base and condensation on the bubble cap.
The size of the primary bubble increased with increasing wall superheat. Strong Marangoni convection around the bubble was observed from the side view video to develop in low- $g$, forming a "jet" of heated fluid into the bulk fluid. This "jet" also provided a reaction force on the primary bubble, keeping the bubble on the heater. Merte et al. (1998) in their space shuttle experiments also observed a primary bubble with smaller bubbles merging with it, but the primary bubble was static on the surface and the smaller bubble moved towards it, unlike in the present study. The primary bubble in their study was also observed to eventually detach slightly from the surface, although intermittent dryout of the surface did occur.

In high- $g$ environments, many small bubbles were observed on the surface at high superheat, with progressively fewer bubbles at lower superheats. Photographs of boiling from below the heater are shown in Fig. 7. At the lowest superheat, boiling was extinguished-only natural convection was observed on the surface.

Space-resolved heat transfer distributions on the array at three superheats are shown in Fig. 8, where each heater has been colored according to the heat transfer (this heat transfer has been corrected for substrate conduction). Low heat transfer is associated with the dry area underneath the primary bubble, while high heat transfer occurs during satellite bubble growth and departure and on the heaters cooled by natural convection.
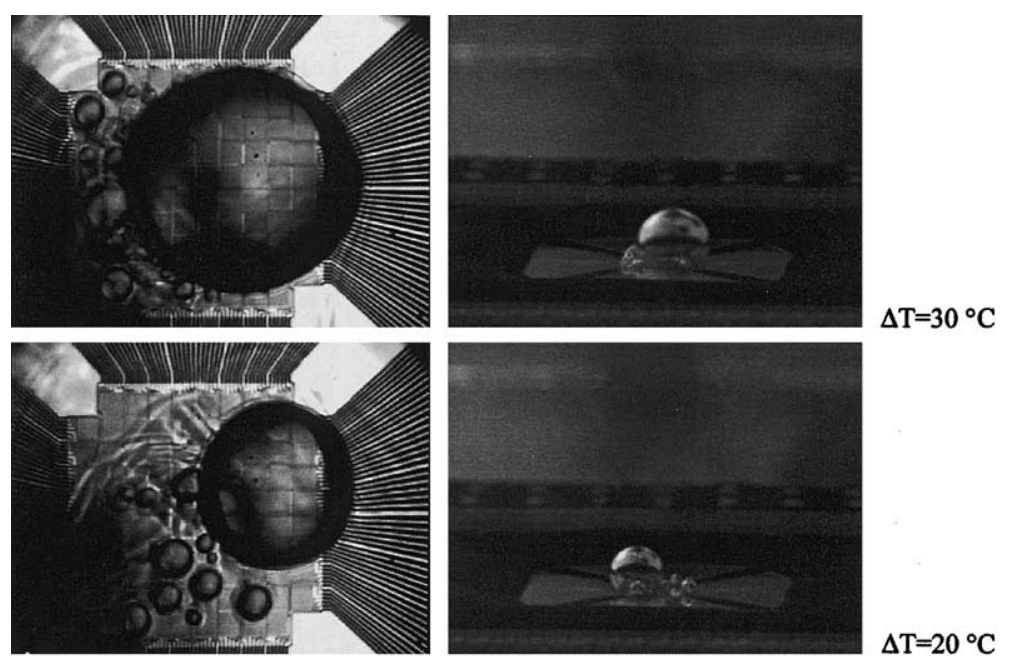

$\Delta \mathrm{T}=30^{\circ} \mathrm{C}$
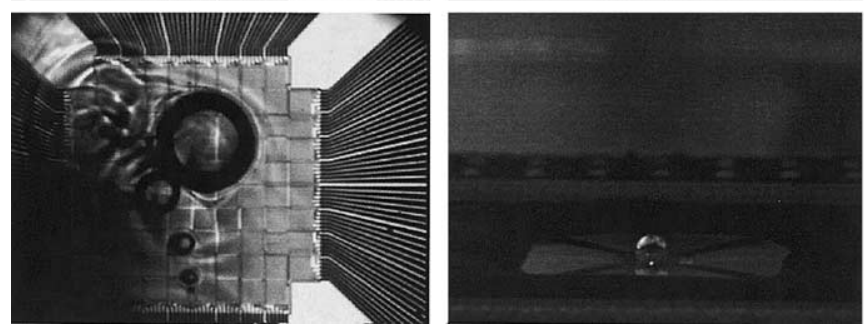

$\Delta \mathrm{T}=20^{\circ} \mathrm{C}$

Fig. 6. Bubble behavior at three superheats during low-g. 


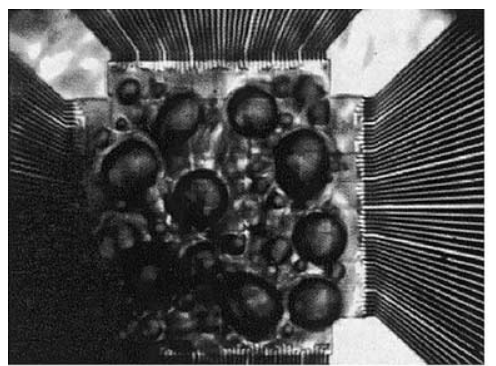

$\Delta \mathrm{T}=30^{\circ} \mathrm{C}$

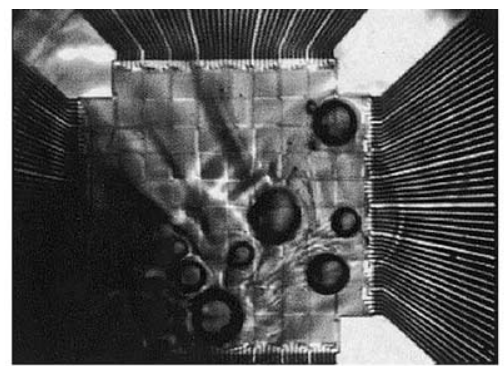

$\Delta \mathrm{T}=20^{\circ} \mathrm{C}$

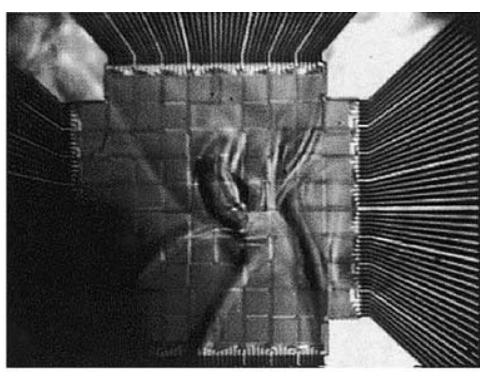

$\Delta \mathrm{T}=10^{\circ} \mathrm{C}$

Fig. 7. Photographs of boiling in the high-g environment.

Occasionally, a satellite bubble grew large enough that the dry area underneath it became larger than a single heater, causing the heat flux from that heater to drop to a low value.

The movement of the primary bubble inferred from the heat transfer data was observed to be more regular in the sounding rocket than on the $\mathrm{KC}-135$. The primary bubble moved in a very periodic, circular motion through the microgravity period for a given wall superheat on the sounding rocket, whereas it was occasionally observed to reverse direction on the KC- 135 . This behavior is most likely due to the larger $g$-jitter on the $\mathrm{KC}-135$. Because video for the sounding rocket flight was not obtained, it is difficult to tell whether or not the $g$-jitter affected the time averaged heat transfer behavior for these highly subcooled cases. It is suspected that $g$-jitter does not affect boiling much in this case since the primary bubbles were relatively small. Recent, unpublished results with the bulk liquid subcooled by 7 ${ }^{\circ} \mathrm{C}$ indicated significant $g$-jitter effects because of the large primary bubble.

\subsection{Individual heat flux traces}

Time-resolved images of boiling on the surface are shown in Fig. 9 for wall superheats of 30 and $20{ }^{\circ} \mathrm{C}$, while heat flux traces for two representative heaters (heaters 14 and 59, see Fig. 5 for their location in the array) are shown in Fig. 10 at wall superheats of 30, 20 and $15{ }^{\circ} \mathrm{C}$. The reader is reminded that the images were acquired at a rate of about $60 \mathrm{~Hz}$, while the data was acquired at $250 \mathrm{~Hz}$, resulting in roughly four data points per image. The small satellite bubbles grew, collapsed, and/or merged with other bubbles more quickly than the image frame rate, so the image shown is the one that corresponds most closely to the heat transfer distribution at the time indicated.

The heat transfer behavior can be correlated with the movement of the primary bubble. For example, consider the case for a wall superheat of $30{ }^{\circ} \mathrm{C}$. At $4.86 \mathrm{~s}$, both heaters 14 and 59 are covered with vapor, and the heat transfer is low. As the primary bubble moves left, it allows liquid to wet heater 59 and bubble nucleation occurs resulting in a sharp increase in heat transfer beginning just after $4.86 \mathrm{~s}$. The small bubble continues to grow, even growing large enough that heater 59 begins to dry out around $4.92 \mathrm{~s}$, as indicated by the dip in heat transfer. When the small bubble moves off heater 59 onto an adjacent heater, a new bubble nucleates on heater 59 at $4.94 \mathrm{~s}$ and the heat transfer increases again. The primary bubble begins moving back in the lower right direction beginning at $4.92 \mathrm{~s}$, and covers heater 59 between $4.98 \mathrm{~s}$ and about $5.02 \mathrm{~s}$, driving the heat transfer low. As the primary bubble moves back towards the upper left after $5.02 \mathrm{~s}$, another nucleation event occurs on heater 59 and the heat transfer increases. Heater number 14 is covered by vapor the entire time shown.

Similar behavior is seen for a superheat of $20^{\circ} \mathrm{C}$. The primary bubble covers both heaters 14 and 59 at $5.06 \mathrm{~s}$. As the primary bubble moves left, heater 59 is wet by the advancing liquid front at $5.08 \mathrm{~s}$ and a bubble is seen to nucleate on this heater. This small bubble seems to move off of the heater at $5.22 \mathrm{~s}$, then move back on to it at $5.26 \mathrm{~s}$. The heat flux trace reveals a sharp dip in the heat transfer at about $5.26 \mathrm{~s}$, indicating that the heater has momentarily dried out as the bubble grows. The advancing primary bubble covers the heater again at $5.32 \mathrm{~s}$. Similar behavior is seen for heater 14, but the time this heater is covered with vapor is longer than that for heater 59 .

The heat flux trace for heater 59 at a superheat of 15 ${ }^{\circ} \mathrm{C}$ shows the heat transfer as the primary bubble passes over it when no nucleation occurs on or near a heater (nucleation occurred on heater 14 at this superheat). A spike in heat flux is observed as liquid rewets the surface as the dry spot passes (e.g., at $4.90 \mathrm{~s}$ ), which is due to transient conduction into the liquid after rewetting of the surface and/or the evaporation of a thin liquid layer at the advancing liquid front. A decay in heat transfer is observed after the primary bubble passes as fluid movement dies out (4.93-5.07 s). Another spike in heat flux occurs just before dryout occurs on the heater $(5.08 \mathrm{~s})$, and is likely due to the evaporation of a thin liquid film at the liquid front. The magnitude of the spike is larger when liquid rewets the surface after the 

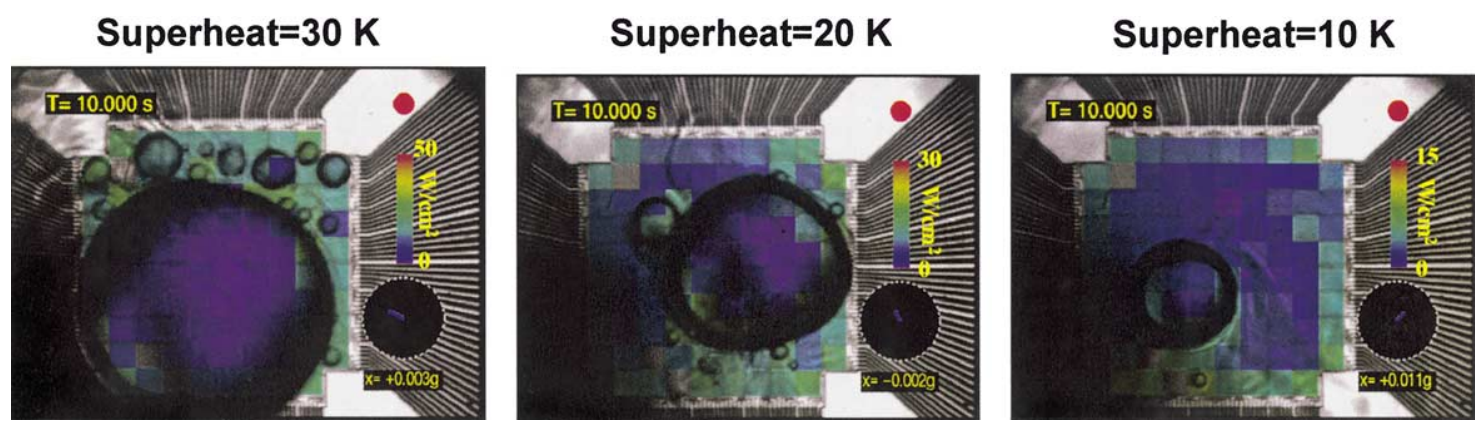

Fig. 8. Space resolved heat transfer distributions on the array.

(a)
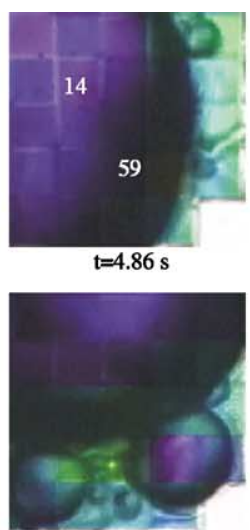

$\mathrm{t}=4.940 \mathrm{~s}$

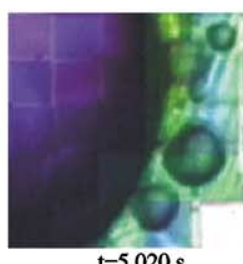

$\mathrm{t}=5.020 \mathrm{~s}$

(b)

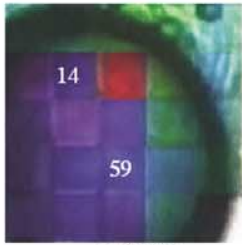

$\mathrm{t}=5.06 \mathrm{~s}$

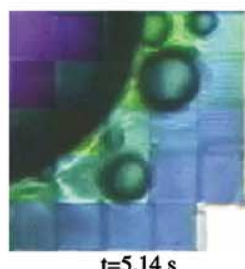

$\mathrm{t}=5.14 \mathrm{~s}$

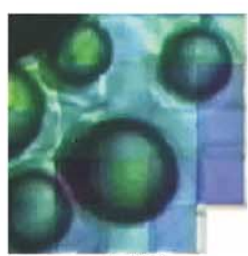

$\mathrm{t}=5.26 \mathrm{~s}$

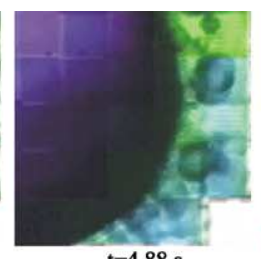

$\mathrm{t}=4.88 \mathrm{~s}$
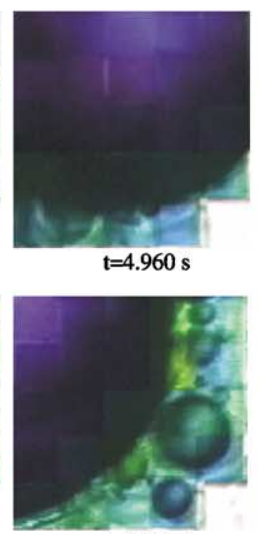

$\mathrm{t}=5.040 \mathrm{~s}$

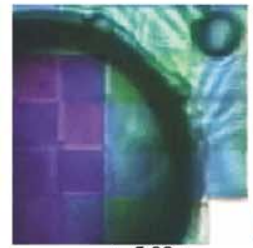

$\mathrm{t}=5.08 \mathrm{~s}$

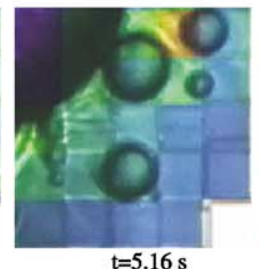

$\mathrm{t}=5.16 \mathrm{~s}$

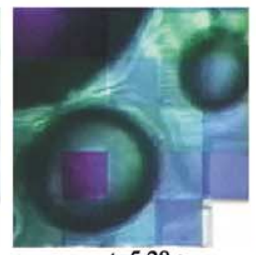

$\mathrm{t}=5.28 \mathrm{~s}$

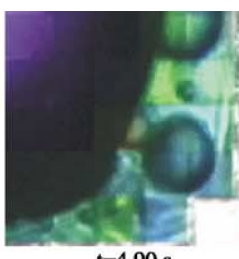

$\mathrm{t}=4.90 \mathrm{~s}$

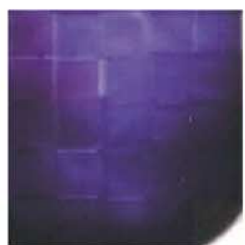

$\mathrm{t}=4.980 \mathrm{~s}$

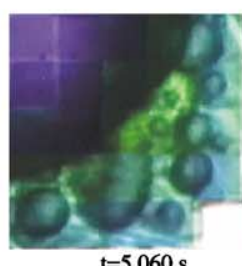

$\mathrm{t}=5.060 \mathrm{~s}$

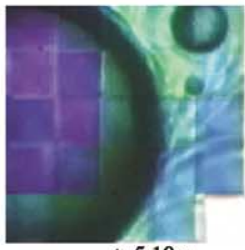

$\mathrm{t}=5.10 \mathrm{~s}$

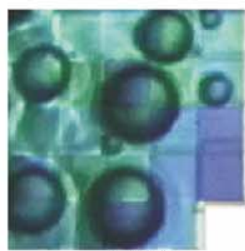

$\mathrm{t}=5.22 \mathrm{~s}$

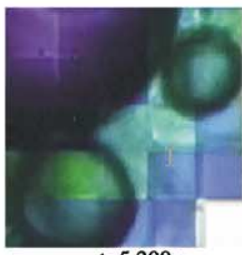

$\mathrm{t}=5.300 \mathrm{~s}$

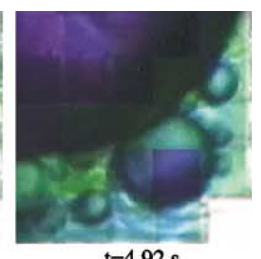

$\mathrm{t}=4.92 \mathrm{~s}$
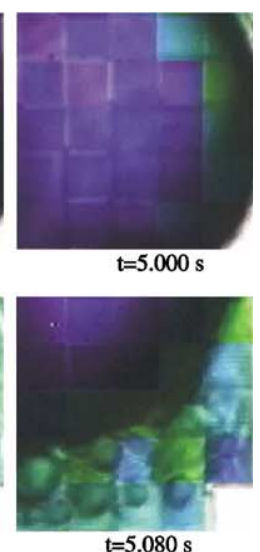

$\mathrm{t}=5.080 \mathrm{~s}$
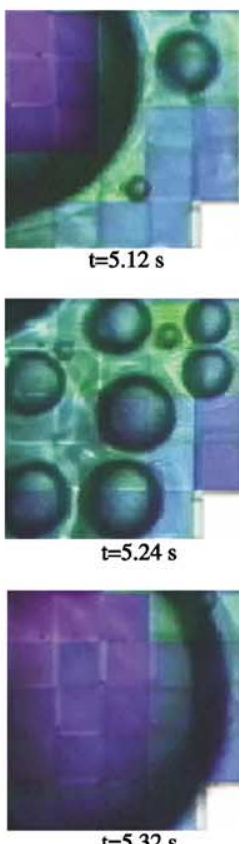

$\mathrm{t}=5.32 \mathrm{~s}$

Fig. 9. Time resolved images of boiling at a wall superheat $=30^{\circ} \mathrm{C}$ (a), $20^{\circ} \mathrm{C}$ (b). 


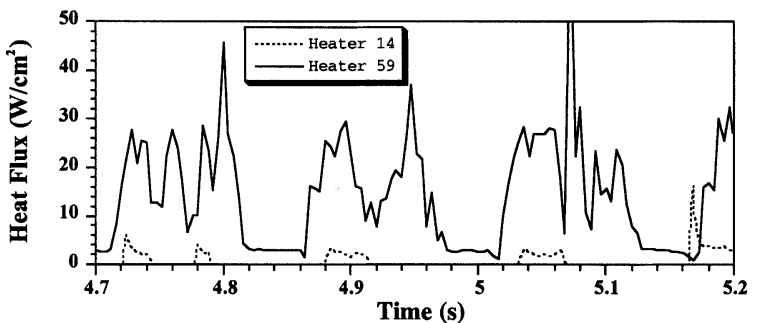

(a). Wall superheat $=30^{\circ} \mathrm{C}$.

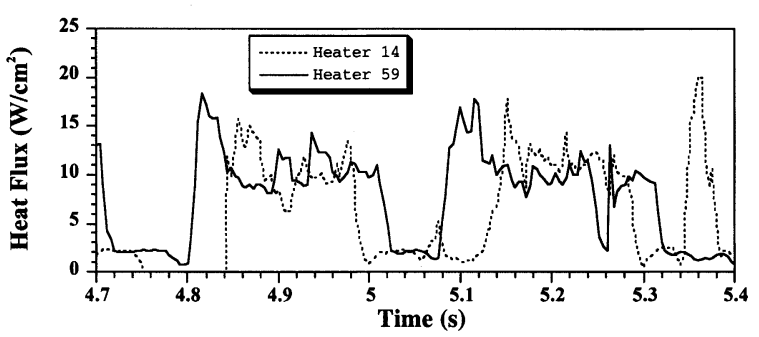

(b). Wall superheat $=20^{\circ} \mathrm{C}$

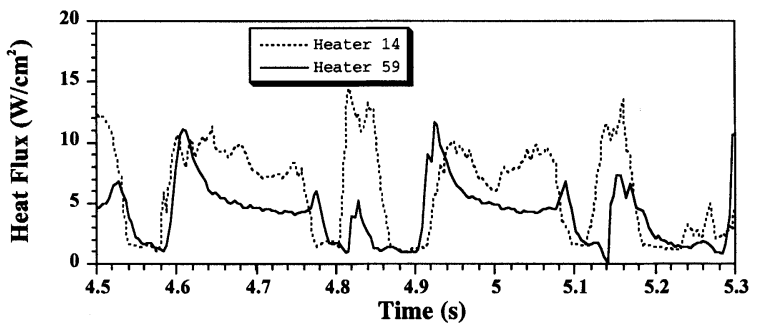

(c). Wall superheat $=15^{\circ} \mathrm{C}$.

Fig. 10. Wall heat flux traces for two heaters in the array in low-g. (a) Wall superheat $=30{ }^{\circ} \mathrm{C}$, (b) $20{ }^{\circ} \mathrm{C}$ and (c) $15^{\circ} \mathrm{C}$.

dry spot passes over the heater. This is consistent with the bubble dynamics. The primary bubble is thought to move on the surface as it merges with the smaller satellite bubbles. The part of the primary bubble close to the wall is "pulled" around the heater, resulting in a change in the contact angles as shown in Fig. 11. For a stationary primary bubble, the nominal contact angle is given by $\alpha_{0}$. For a "pulled" bubble, $\alpha_{\mathrm{a}}>\alpha_{0}$, while $\alpha_{\mathrm{r}}<$ $\alpha_{0}$ becomes smaller. The thinner liquid layer associated with $\alpha_{\mathrm{r}}$ would result in higher heat transfer. The opposite is expected to occur for a bubble being "pushed" along the wall in flow boiling.

\subsection{Boiling curve}

Boiling curves were generated from data taken on the sounding rocket, the KC-135, and in earth gravity. The KC-135 data was split into low- $g$ and high- $g$ data, with boiling curves being generated for each. Comparison of this data with low- $g$ and earth gravity data taken at saturated conditions using a different heater array and test rig (see Kim et al., 2001) is shown in Fig. 12. Significant differences between earth gravity, high-g, and low- $g$ data are observed. First, all of the subcooled heat

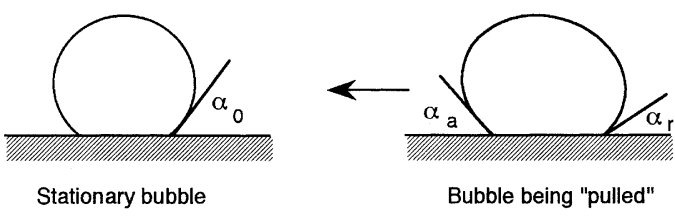

Fig. 11. Schematic illustrating how bubble contact angles change as the bubble moves on the surface.

fluxes (the data taken during this program) are significantly higher than those for saturated conditions due to the increase in the natural convection heat transfer. Part of the difference in heat fluxes could, however, be due to different nucleation site density distributions since different heater arrays were used to take the saturated and subcooled data. Second, earth gravity heat fluxes are seen to be lower than both the low- $g$ and high- $g$ data taken on the $\mathrm{KC}-135$ at superheats below $25{ }^{\circ} \mathrm{C}$. The sounding rocket data falls between the two. It should be noted that the earth gravity data taken before the sounding rocket was launched and after the KC-135 data was taken (almost eight months apart) agree, indicating that both the heater array and control electronics were stable throughout the test program. Calibration of the heater array before the sounding rocket launch and after the $\mathrm{KC}-135$ tests were completed also revealed very little shift in the calibration, further indicating that the electronics and heater array were stable. The differences between the boiling curves

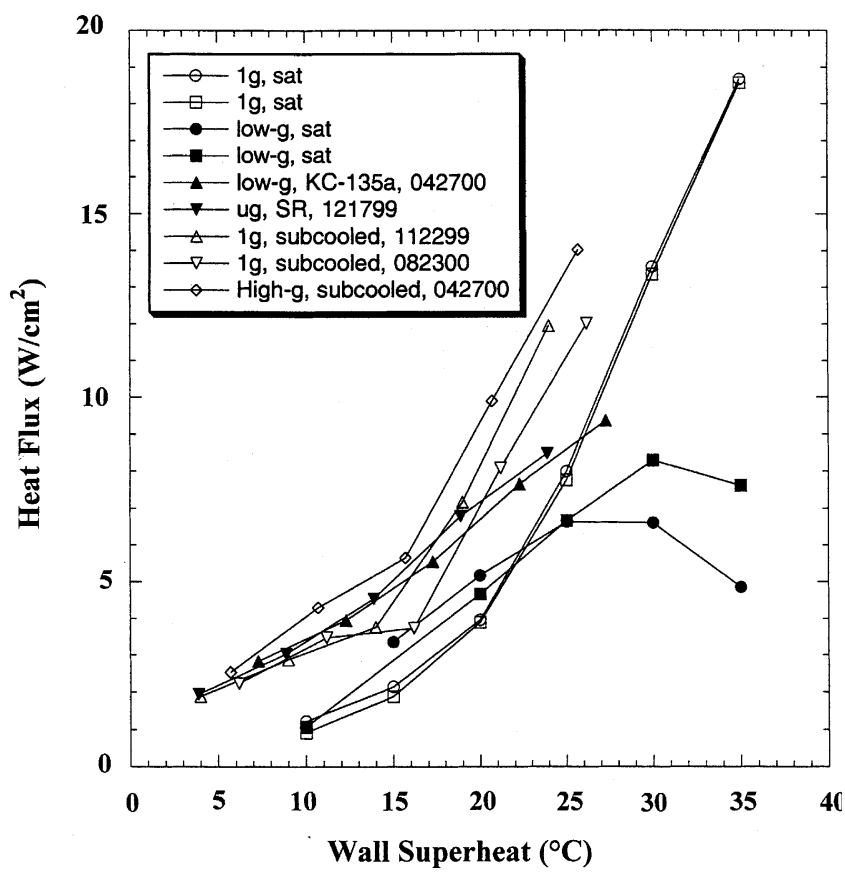

Fig. 12. Boiling curves in earth, low gravity, and microgravity at saturated and subcooled conditions. 
are therefore due to some change in the boiling structure on the surface. Third, the low- $g$ data and high- $g$ data taken in the $\mathrm{KC}-135$ are seen to agree with each other for wall superheats below $25 \mathrm{~K}$, despite the large difference in bubble behavior on the surface. Fourth, the low- $g$ heat fluxes at the highest wall superheat $\left(30^{\circ} \mathrm{C}\right)$ fall below those for earth gravity and high- $g$ environments due to the primary bubble covering a large portion of the heater in low- $g$. This is discussed further in the next section.

The reason for the shift in the boiling curve between the earth gravity data and the other data is not currently known. It is interesting to note that both the low- $g$ and high- $g$ data fall above the earth gravity data, indicating that shifts in the boiling curve are not monotonic with gravity.

The boiling curves are consistent with the observations of Merte et al. (1998) who observed higher heat transfer in microgravity than earth gravity at low superheats, but significantly lower critical heat fluxes in microgravity. They also observed increases in heat transfer in microgravity as subcooling increased.

\subsection{Space and time resolved heat transfer}

Boiling curves obtained from those areas of the heater on which boiling occurred (i.e., the heaters are ignored when only natural convection occurs on the heater, or if the heater goes dry due to the primary bubble) are shown in Fig. 13. It is seen that this "boiling heat flux" is quite independent of the gravity level even at the highest wall superheat, indicating that the smallscale bubble heat transfer is independent of the gravity level. This suggests that if one is able to predict the extent of the dry area in microgravity, then one should be able to predict the microgravity boiling curve from earth gravity boiling heat flux data.

\subsection{Bubble size distribution}

Images from the video were examined during low- $g$, high-gravity, and earth-gravity at four levels of wall superheat $\left(30,25,20\right.$ and $\left.15^{\circ} \mathrm{C}\right)$. The number of bubbles was measured from video frames at $0.1 \mathrm{~s}$ intervals until a sample of over 60 bubbles had been collected. This procedure was repeated for the twelve conditions above. An average bubble density (\# bubbles $/ \mathrm{mm}^{2}$ ) was then calculated. For the high-gravity and earth gravity conditions the bubble density was generated at each wall superheat by averaging the number of bubbles per video frame and dividing by the total heater area. For the low$g$ condition the area was taken to be the total heater area less the average area covered by the dry spot (associated with the primary bubble). The bubble densities are plotted in Fig. 14. The bubble densities were found to be

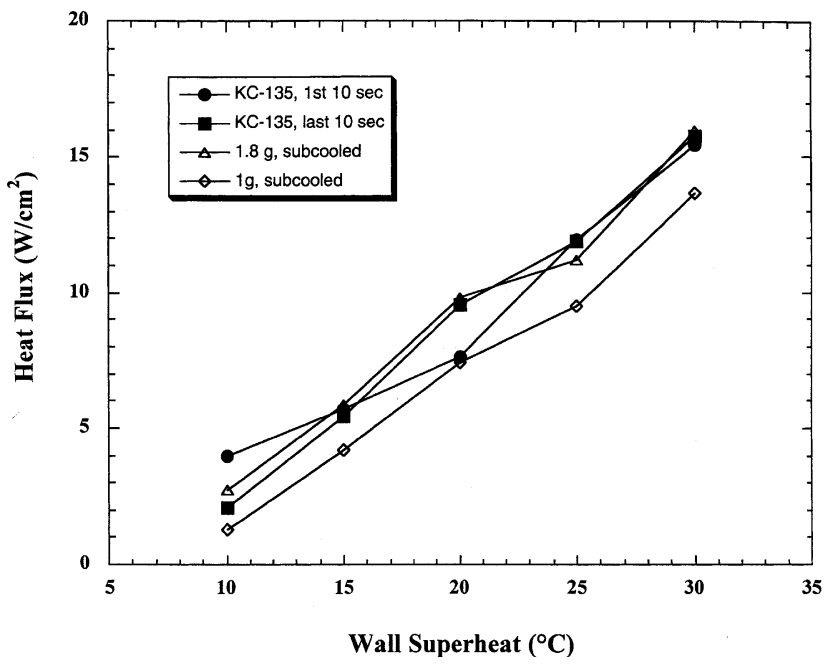

Fig. 13. Boiling heat flux in low-g, earth gravity, and high-g.

independent of gravity level at each wall superheat, which agrees with the independence of the "boiling heat flux" with gravity level seen in Fig. 13. In addition, the bubble density and "boiling heat flux" appear to follow similar trends with superheat for the three levels of gravity.

Bubble diameters were also measured from the same digitized video frames. Histograms of bubble diameter were generated using 9 bins between 0 and $0.8 \mathrm{~mm}$. Since the number of bubbles in each sample varied from 60 to 72 bubbles, the frequency of observations in each bin was normalized by dividing by the total number of bubbles in the sample. Shown in Fig. 15 are histograms

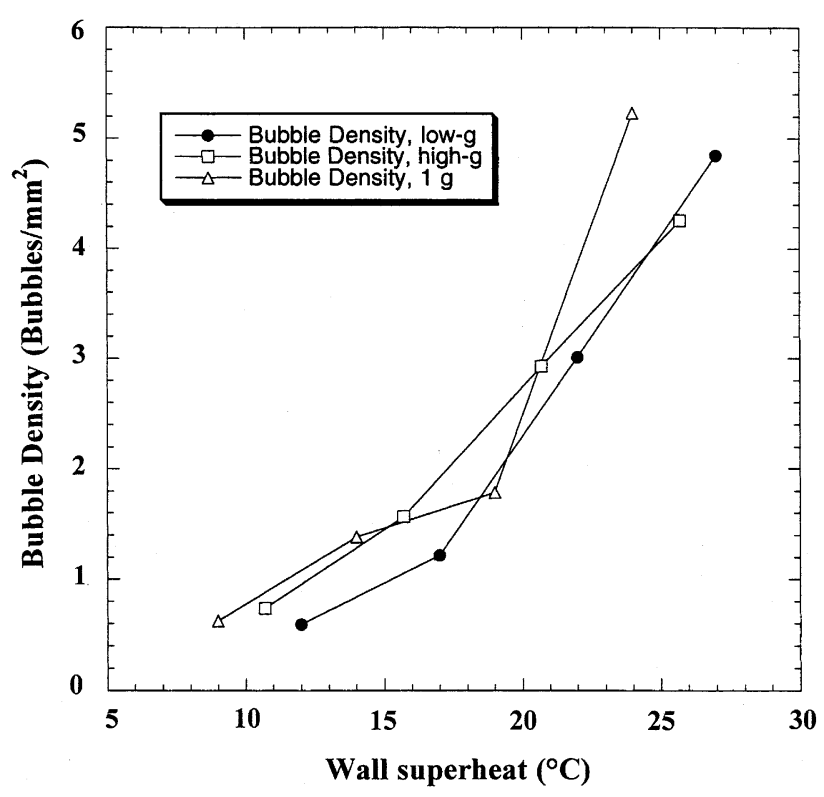

Fig. 14. Bubble density variation with wall superheat at three gravity levels. 


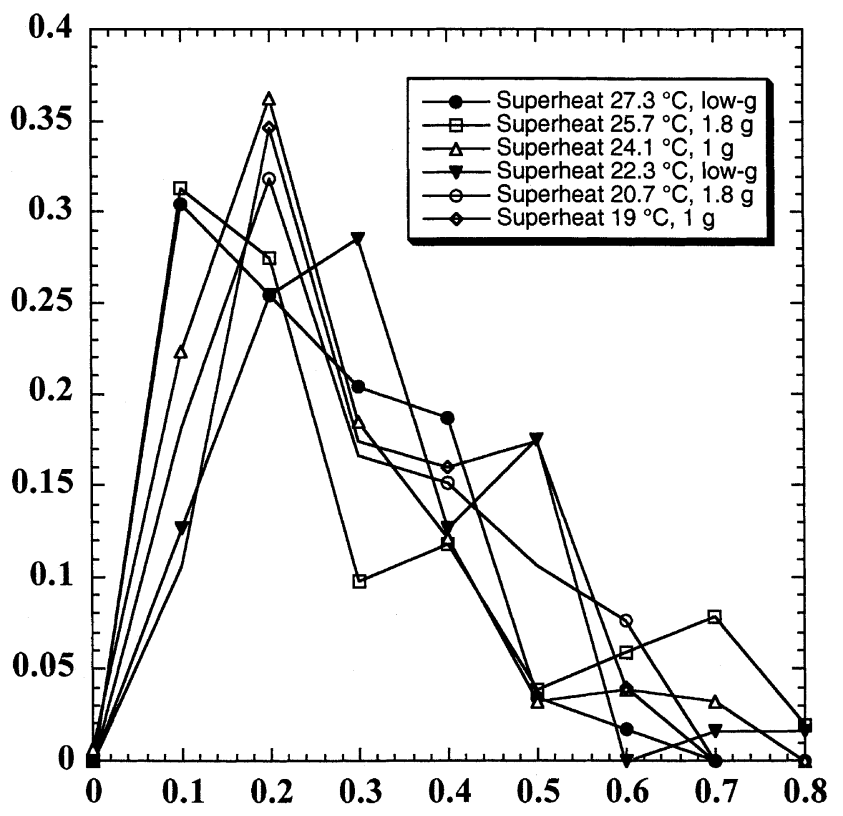

Fig. 15. Histogram of bubble diameters at two wall superheats and three gravity levels.

of bubble diameter for the three g-levels at the two highest superheats. This plot indicates that the bubble size distribution appear to be similar. In order to establish whether the distribution of bubble diameters were related, a Wilcoxon rank sum test was performed. This is a nonparametric test used to compare two nonnormally distributed groups. The test produces a value $P$ which answers the question, "If the median difference between the two groups really is zero, what is the chance that the random sampling would result in a median difference as far, or farther from zero as observed in the test?". Typically a $P$ value of greater than 0.05 indicates that the populations generated by the two samples are statistically identical. Tests between the three levels of gravity at 30 and $25{ }^{\circ} \mathrm{C}$ are shown in Fig. 16. The medians, minimum and maximum values of diameter in each sample are shown in Table 1 . The $P$ values are seen to be much greater than 0.05 for the tests between the samples for both 30 and $25^{\circ} \mathrm{C}$, indicating that the distribution of bubble diameters is independent of the gravity level.
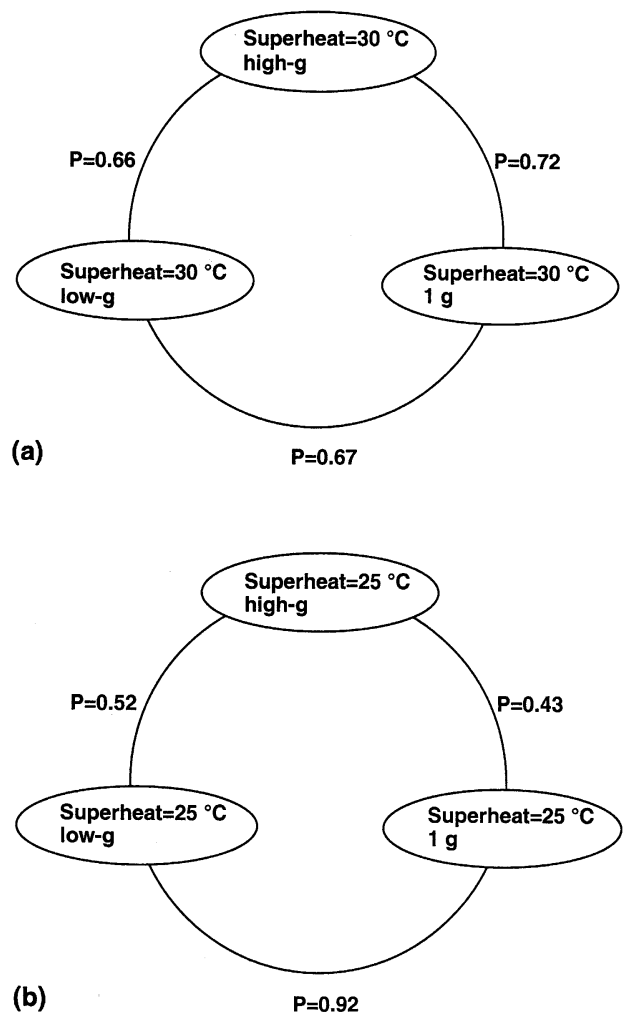

Fig. 16. Summary of Wilcoxon rank sum test.

\section{Conclusions}

A sounding rocket payload to study subcooled boiling in microgravity on a small, flat surface held at constant temperature was designed, built, and flown. Over $200 \mathrm{~s}$ of high quality microgravity were obtained. Additional data at high- $g$ and in low- $g$ were later obtained on the KC-135. Earth gravity data were obtained before the sounding rocket flight, as well as before and after the KC-135 flights. Visual data were acquired for all runs except the sounding rocket flight. The main conclusions of this study are summarized below.

1. Steady state boiling was observed in microgravity and low- $g$ under subcooled conditions. A large primary bubble was observed to form on the surface due to coalescence. This primary bubble moved over the surface coalescing with smaller satellite bubbles.

Table 1

Median, minimum, and maximum bubble sizes at two superheats and three gravity conditions

\begin{tabular}{lllll}
\hline Wall superheat $\left({ }^{\circ} \mathrm{C}\right)$ & Gravity environment & Median $(\mathrm{mm})$ & Minimum $(\mathrm{mm})$ & Maximum $(\mathrm{mm})$ \\
\hline 30 & Low- $g$ & 0.22 & 0.06 & 0.63 \\
30 & High- $g$ & 0.19 & 0.06 & 0.77 \\
30 & Earth gravity & 0.23 & 0.04 & 0.71 \\
25 & Low- $g$ & 0.27 & 0.06 & 0.78 \\
25 & High- $g$ & 0.25 & 0.06 & 0.62 \\
25 & Earth gravity & 0.31 & 0.08 & 0.60 \\
\hline
\end{tabular}


2. Boiling curves for low-g and high-g were similar at lower wall superheats. Heat fluxes for high-g were greater at higher superheats due to the growth of the primary bubble on the surface in low-g.

3. The earth gravity heat fluxes were slightly lower than the high- $g$ heat fluxes at all superheats.

4. Space and time resolved heat transfer revealed low heat transfer associated with the large primary bubble in low- $g$, and large amounts of heat transfer with the satellite bubbles.

5. The heat flux associated with the satellite bubbles were similar to the heat fluxes obtained at earth and low-g levels, indicating little effect of gravity on the small-scale boiling.

\section{Acknowledgements}

This work was supported by the NASA Microgravity Fluid Physics Program under Grant no. NAG-32228. Their support is gratefully acknowledged. Mr. Joe Balombin and Mr. John McQuillen were the grant monitors. The colored photos showing heat transfer distributions on the surface were processed by Ms. Mary Vickerman of the GVIS Lab, NASA Glenn Research Center. Redesign of the feedback loop boards and the data acquisition system was performed by Mr. Richard Quine of the University of Denver.

\section{References}

Bae, S., Kim, M.H., Kim, J., 1999. Improved technique to measure time and space resolved heat transfer under single bubbles during saturated pool boiling of FC-72. Experimental Heat Transfer 12 (3), 265-278.

Clark, J.A., 1968. Gravic and agravic effects in cryogenic heat transfer. Advances in Cryogenic Heat Transfer 87 64, 93-102.

Di Marco, P., Grassi, W., 2000. Pool boiling in microgravity: assessed facts and open issues, Keynote paper. In: Hahne, E.W.P., Heidemann, W., Spindler, K. (Eds.), Proceedings of the Third European Thermal-Sciences Conference, Heidelberg. ETS, Pisa, pp. 81-90.
Kim, J., Yaddanapuddi, N., Mullen, J.D., 2001. Heat transfer behavior on small horizontal heaters during saturated pool boiling of FC-72 in microgravity. Microgravity Science and Technology XII, 116-127.

Lee, H.S., Merte, H., 1998. Pool boiling phenomena in microgravity. In: Proceedings of the 11th International Heat Transfer Conference, Kyongju, Korea, vol. 2, pp. 395-400.

Merte, H., Lee, H.S., Keller, R.B., 1998. Dryout and rewetting in the pool boiling experiment flown on STS-72 (PBE-IIB) and STS-77 (PBE-IIA).

Ohta, H., Kawaji, M., Azuma, H., Kawasaki, K., Tamaoki, H., Ohta, K., Takada, T., Okada, S., Yoda, S., Nakamura, T., 1997. TR-1A rocket experiment on nucleate boiling heat transfer under microgravity. In: ASME-MEMS, HTD-vol. 354, pp. 249-256.

Oka, T., Abe, Y., Mori, Y.H., Nagashima, A., 1995. Pool boiling of $n-$ pentane, CFC-113, and water under reduced gravity: parabolic flight experiments with a transparent heater. Journal of Heat Transfer 117, 408-417.

Rule, T.D., Kim, J., 1999. Heat transfer behavior on small horizontal heaters during pool boiling of FC-72. Journal of Heat Transfer 121 (2), 386-393.

Siegel, R., 1967. Effects of reduced gravity on heat transfer. In: Advances in Heat Transfer, vol. 4. Academic Press, New York/ London, pp. 143-228.

Siegel, R., Keshock, E.G., 1964. Effects of reduced gravity on nucleate boiling bubble dynamics in saturated water. Journal AIChE 4 10, 509-517.

Straub, J., 2001. Boiling heat transfer and bubble dynamics in microgravity. In: Advances in Heat Transfer, vol. 35. Academic Press, New York, pp. 57-172.

Straub, J., Zell, M., Vogel, B., 1990. Pool boiling in a reduced gravity field. In: Proceeding of the Ninth International Heat Transfer Conference, Jerusalem, Israel. Hemisphere, New York, pp. 91-112.

Vogel, B., Straub, J., 1992. Single bubble experiments in pool boiling. In: Proceedings of Eigth European Symposium on Materials and Fluid Sciences in Microgravity, Brussels, Belgium, ESA SP-333, pp. 879-886.

Zell, M., Straub, J., Vogel, B., 1989. Pool boiling under microgravity. Journal of Physicochemical Hydrodynamics 11 (5/6), 813-823.

Zell, M., Straub, J., Vogel, B., 1990. Heat transfer in pool boiling under microgravity. Soviet Journal of Low Temperature Physics 16 (5), 323-324.

Zell, M., Straub, J., Weinzierl, A., 1984. Nucleate pool boiling in subcooled liquid under microgravity-results of Texus experimental investigations. In: Proceedings of the Fifth European Symposium on Material Sciences under Microgravity, Schloss Elmau, ESA SP-222, pp. 327-333. 